\title{
LOS CARACTERES DE LA LEY ARAGONESA DEL BANCO DE TIERRAS*
}

\author{
POR \\ Fernando López Ramón \\ Catedrático de Derecho Administrativo
}

SUMARIO: I. UNA LEY POLÉMICA: A) Las críticas. B) La falta de una información adecuada. - II. UnA LeY Incomprendida: A) Apéndice de la Ley de Reforma y Desarrollo Agrario. B) Ley no expropiatoria. C) Bienes del Banco de Tierras. D) Explotación del Banco de Tierras. E) Gestión del Banco de Tierras. - III. UNA LEY DE ORIGEN MUNICIPAL Y DE FINALIDAD ANTIDESAMORTIZADORA: A) Los acuerdos sobre comunales de 1984. B) EI fundamento antidesamortizador.-IV. UNA LEY PARA LA REForma aGRARIA PERMANENTE.-V. UNA LEY INAPLICADA Y PENDIENTE DE DEROGACIÓN: A) La inaplicación. B) La Proposición de Ley sobre el Patrimonio Agrario.

\section{UNA LEY POLEMICA}

Ley polémica, incomprendida, de origen municipal y finalidad antidesamortizadora, favorecedora de una reforma agraria permanente, pero inaplicada y pendiente de derogación. En esos cinco elementos creo que pueden resumirse los caracteres de la Ley Aragonesa 3/1987, de 10 de marzo, del Banco de Tierras.

\section{A) Las críticas}

Se trata, efectivamente, de una Ley cuyo contenido ha levantado gran polémica, lloviendo los calificativos sobre la misma. «Sin duda, el proyecto más original, novedoso y polémico de cuantos se han tramitado en la Cámara autónoma», decía el Heraldo de Aragón de 20 de noviembre de 1986, al presentar ante la opinión pública el correspondiente proyecto de Ley.

Los enfrentamientos dialécticos a propósito de la norma se formalizaron y cobraron resonancia a raíz del debate público sobre el proyecto que abrió la Comisión de Agricultura y Ganadería de las Cortes de Aragón. Sindicatos Agrarios, Comunidades de Regantes, Ayuntamientos y Cámaras Agrarias, entre otras instituciones, fueron convocadas para exponer su opinión ante el órgano parlamentario. UAGA, los Ayuntamientos controlados por los socialistas y algunas

\footnotetext{
* Texto de la ponencia presentada en las VII Jornadas Cooperativas, sobre alnstituciones para una reforma agraria», celebradas en Lérida los dís 7 y 8 de abril de 1989.
} 
Cámaras Agrarias consideraron, sin perjuicio de matices, que el Banco de Tierras suponía un avance en el régimen de explotación de los nuevos regadios. Por el contrario, ARAGA, Jóvenes AgricultoresUFADE $y$, en general, las Comunidades de Regantes tacharon al proyecto como introductor de un nuevo dirigismo administrativo en el ámbito privado, determinante de un grave atentado contra el Derecho de propiedad. En el sentir de los críticos, el Banco de Tierras no podía funcionar, al prescindir de la ilusión del agricultor por cultivar su propia finca. Se dijo también que la Diputación General de Aragón iba a configurarse como un gran señor feudal, el mayor propietario de tierras en Europa. Y, por último, se destacó la positiva experiencia de la normativa de colonización aplicada en España desde los años 40.

En la prensa diaria surgieron también las críticas y las descalificaciones. Cristóbal Montés hablaba de las «imperfecciones técnicas» del proyecto (Heraldo de Aragón, 13 de diciembre de 1986), que Sanz Jarque tildaba de «ley conservadora y retrógrada» (Heraldo de Aragón, 16 de diciembre de 1986) y Jovellanos de «norma que en principio atenta contra el sentido de la propiedad privada» $(A B C, 26$ de abril de 1987).

Incluso la integrista Sociedad Covadonga difundió un folleto en febrero de 1988 afirmando que «un obispo y 240 sacerdotes aragoneses piden la derogación total de la Ley del Banco de Tierras», en la que se identificaba el «rumbo al comunismo».

\section{B) La falta de una información adecuada}

Ley polémica. Creo que no hacen falta mayores pruebas al respecto. En cambio, quizá sea conveniente ofrecer alguna reflexión acerca del proceso informativo que rodeó al Banco de Tierras. La escasa distancia temporal desde la aprobación de la Ley no permite todavía, en la actualidad, hablar de un enfriamiento de las pasiones que posibilite el juicio objetivo sobre lo ocurrido. Pero, sin embargo, el discurrir de los acontecimientos políticos en Aragón, con el aparcamiento, en lo que aquí nos interesa, de la idea el Banco de Tierras, proporciona una cierta capacidad de análisis.

En este tono objetivo-subjetivo diré que, a mi juicio, se cometieron errores en la presentación y defensa pública del contenido de la Ley del Banco de Tierras. El proyecto no había sido un texto improvisado, ni carecía de fundamentos sólidos; sin embargo, ante la opinión pública, esos fundamentos no trascendieron. El aluvión de eslóganes ideados contra la Ley sepultó las escasas iniciativas favorables a su contenido. El Ejecutivo socialista se limitó prácticamente a registrar en las Cortes aragonesas el proyecto de Ley y a seguir su tramitación parlamentaria, buscando, sí, el apoyo de otros grupos políticos 
- apoyo que concedieron comunistas y centristas-, pero sin reparar en que el debate se había trasladado a la calle.

El agricultor prefiere ser propietario; ésa fue la máxima lanzada insistentemente por la opinión conservadora en los ámbitos político y social. Máxima simplificadora, sin duda, pero dotada de notable fuerza expansiva. Expresa una verdad evidente, en términos generales: naturalmente que el. agricultor quiere ser propietario y, además, propietario rico y próspero. Sucede que la cuestión a debatir no es ésa precisamente. La opción, en términos sencillos, se situaría entre vender unas tierras transformadas en regadío o cederlas en uso con una fórmula que proporcionara estabilidad y contenido económico. Vender implica pagar una cantidad elevada, lo cual, por más facilidades que se den al comprador, hace que esta alternativa se incline en favor de determinadas clases sociales, sin que, por añadidura, una vez consumada la venta, sea fácil mantener las explotaciones de tipo medio cultivadas directa y personalmente por su propietario. La cesión en uso, en cambio, puede beneficiar a clases sociales más modestas $y$, además, permite la permanencia de la reforma agraria, bajo un control público.

La vieja Legislación Colonizadora aplicada desde los años 40 , con su opción propietaria, ha sido defendida, en términos más serios y atendibles, por algunos detacados Ingenieros, protagonistas de su práctica en Aragón (De los Ríos, Palou). Sin duda fue enorme el esfuerzo realizado por los colonos y por los técnicos en aquel tiempo; pero el canto a las virtudes de la Legislación Colonizadora, hecho para el presente, prescinde por completo de la diferente realidad social española. Cada vez más es el aspecto empresarial el que prima en todos los ámbitos económicos; el dinamismo requerido en las explotaciones agrarias no precisa del soporte de la propiedad fundiaria.

Por estas vías pienso que debería haberse conducido la defensa pública del Banco de Tierras. Se cayó, sin embargo, en el formalismo. No se supo "vender" la reforma. Por eso, la Ley del Banco de Tierras nació lastrada, con enormes dificultades sociales para su puesta en práctica.

En todo caso, una Ley polémica $y$, en cuanto tal, una Ley incomprendida, puesto que la simplificación de los mensajes lanzados en el debate público impidió, en buena medida, un conocimiento cabal de su contenido (sin perjuicio, ciertamente, de excepciones entre los especialistas, como es el caso del documento estudio de José Tudela Aranda, «Comunidad Autónoma y reforma agraria: la Ley del Banco de Tierras de Aragón", publicado en Revista de Administración pública, núm. 114 de 1987, pp. 415-452). Intentemos penetrar 
en ese contenido, aunque sin abandonar el tono de exposición general hasta ahora mantenido.

\section{UNA LEY INCOMPRENDIDA}

\section{A) Apéndice de la Ley de Reforma y Desarrollo Agrario}

Por más trascendencia que quiera darse a la Ley del Banco de Tierras, lo cierto es que, sistemáticamente, es un simple apéndice a la Ley de Reforma y Desarrollo Agrario de 1973, sin cuyo conocimiento, en consecuencia, no es posible comprender el alcance de la reforma aragonesa.

La Ley de Reforma y Desarrollo Agrario, recogiendo instituciones y técricas de la Legislación Colonizadora, prevé las Grandes Zonas de Interés Nacional (arts. 92 y ss.) como una de las actuaciones de reforma agraria. La actividad pública en esas Grandes Zonas, declaradas por Decreto, se orienta, en el aspecto más significativo, a la transformación en regadio de una amplia superficie territorial, transformación que supone la necesidad de muy cuantiosas inversiones públicas en obras de infraestructura variadas.

Conviene reparar en que esa actividad pública no persigue únicamente la puesta en regadío, sino también el destacado objetivo de constituir unas explotaciones agrarias de tipo medio. Favorecer el establecimiento y desarrollo de una clase media agraria ha sido siempre aspiración de nuestras leyes de reforma agraria, desde la época de la llustración, salvado quizás algún período exaltado - aunque históricamente comprensible-durante la Segunda República.

Pues bien, la constitución de esas explotaciones medias se consigue, en la Ley de Reforma y Desarrollo Agrario, a través de la expropiación de las llamadas tierras «en exceso", que son las que quedan en la Zona, después de determinadas reservas y excepciones en beneficio, por ejemplo, de los antiguos propietarios. Con las tierras «en exceso" se constituyen nuevas explotaciones, cuya superficie suele oscilar entre las diez y las veinte hectáreas. Esas explotaciones son cedidas a agricultores modestos, en el diseño de la Ley, quienes las disfrutan, primero en régimen de concesión administrativa y después, pagado ya el precio estipulado, en régimen de propiedad.

En esta fase es precisamente donde opera la Ley del Banco de Tierras, estableciendo que las tierras en exceso expropiadas se conserven en propiedad por la Comunidad Autónoma de Aragón, que únicamente cedería el uso de las explotaciones a los agricultores. Tal es el mecanismo básico de la Ley, el que suscita mayores problemas 
y también aquel sobre el que giraban las posibilidades reales de la Ley del Banco de Tierras; pues aunque la norma se refiere a otras masas de bienes, las superficies significativas se ubican en las tierras en exceso expropiadas en Bárdenas (unas 14.000 hectáreas) y en las que se expropien en Monegros.

\section{B) Ley no expropiatoria}

Un punto a destacar aquí. De conformidad con lo dicho, no es cierto que la Ley del Banco de Tierras sea una Ley expropiatoria, como a veces se ha afirmado. El mecanismo expropiatorio está previsto en la Ley de Reforma y Desarrollo Agrario de 1973 que, insisto, se limita a recoger normas de etapas anteriores. La expropiación resulta absolutamente necesaria, tanto para formar las explotaciones agrarias de tipo medio, como para llevar a cabo las obras y las reestructuraciones requeridas por la transformación de una Gran Zona.

¿Por qué se ha dicho que la Ley del Banco de Tierras era una Ley expropiatoria? Probablemente en tal punto opera un confusionismo a propósito de una cuestión litigiosa. Se trata del problema de la calificación de amplias masas de bienes comunales en las Cinco Villas. Las familias tradicionalmente «llevadoras» del comunal sostienen que son propietarias de las superficies que cultivan o, al menos, que el tiempo ha consolidado en su favor algún tipo de derecho sobre la tierra. La Administración del Estado, la Autonómica y, al menos en algún momento, las Administraciones locales implicadas han considerado que la propiedad del comunal correspondía a los Ayuntamientos. Viejo pleito, difícil sin duda de solucionar, pero pleito, en todo caso, sobre el que no se pronuncia la Ley del Banco de Tierras. Si el comunal de Bárdenas está dividido en gran número de propiedades privadas - cuestión que deben aclarar los Tribunales-, simplemente sucederá que habrá menos tierras en exceso en la zona, que, en consecuencia, las expropiaciones practicadas podrán ser anuladas y que accederá una superficie agraria menor al Banco de Tierras.

Guste o no guste, la Administración que entiende actúa legítima y lícitamente, no queda paralizada por las reivindicaciones de los particulares, conforme al general principio de autotutela administrativa. Administrativamente se ha constatado la existencia de tierras en exceso $y$ se ha procedido a practicar unas expropiaciones que determinan la constitución de unas importantes superficies de propiedad pública. Sobre estas superficies ya expropiadas actúa la Ley del Banco de Tierras; pero es que sobre esas mismas superficies actuaría, caso de no existir tal Ley, la Ley de Reforma y Desarrollo Agrario. 
Es más, de aplicarse el sistema de la Ley de Reforma y Desarrollo Agrario, se desencadenaría un proceso de acceso a la propiedad por parte de los nuevos colonos, que sería más difícil incluso de modificar que las situaciones concesionales generadas por la Ley del Banco de Tierras. Me refiero al caso -que he de decir, a mí me parece improbable- de que los Tribunales terminaran calificando como propietarios a los «llevadores» del comunal en las Cinco Villas.

Problemas de fondo. Sin duda. Pero también, muy claramente, destacar que la Ley del Banco de Tierras no es una Ley de contenido expropiatorio.

\section{C) Bienes del Banco de Tierras}

Banco de Tierras fue la denominación elegida para designar un patrimonio agrario de la Comunidad Autónoma de Aragón, sometido a un específico régimen jurídico. A ese régimen jurídico pueden acceder bienes de distintas procedencias (arts. 3 a 13).

a) En primer lugar, los adquiridos por la Comunidad Autónoma en virtud de procedimientos de transformación de Grandes Zonas. Constituían, como ya he dicho, la masa principal sobre la que se pensaba actuar. La integración de estos bienes en el Banco de Tierras no es automática, puesto que se requiere una expresa decisión de la Diputación General de Aragón (art. 4.1).

Cabe observar que la Ley aquí no afecta a inmuebles adquiridos -normalmente, por expropiación- en antiguos procedimientos de transformación de Grandes Zonas, sobre los que se haya iniciado el acceso a la propiedad de los colonos, conforme al sistema de la Ley de Reforma y Desarrollo Agrario. Unicamente, el artículo 4.2 de la Ley del Banco de Tierras permite su aplicación a tales inmuebles si se encuentran en la fase de concesión administrativa (que dura hasta el pago del precio del lote por el colonol y es declarada la caducidad de tal concesión conforme a lo dispuesto en la propia Ley de Reforma y Desarrollo Agrario; es decir, caso de que no exista ya ningún derecho pendiente de perfección por parte del antiguo colono.

b) Los artículos 6 a 8 de la Ley establecen un derecho de adquisición preferente a favor de la Diputación General de Aragón en toda enajenación de antiguos lotes, consolidados ya en propiedad, dentro de zonas transformadas, donde se detecta un proceso de acumulación de tierras. Sucede con frecuencia apreciable que, pasada la primera generación de colonos, los descendientes no muestran interés en continuar la explotación, por no ser ya agricultores profesionales; enajenan y el mercado marca sus reglas lógicas, que, como es sabido, no favorecen en este punto al agricultor 
profesional. Pues bien, para evitar que desaparezcan las explotaciones de tipo medio, la Ley prevé la posibilidad de integrarlas en el Banco de Tierras, a través del ejercicio de unos derechos de tanteo y retracto por parte de la Diputación General de Aragón.

c) En los artículos 9 a 11 de la Ley se posibilita la cesión de uso, onerosa o gratuita, de inmuebles pertenecientes a cualquier Ente público, para integrarlos en el Banco de Tierras, por un plazo mínimo de treinta años.

Esta previsión se relaciona con la intención de la propia Ley del Banco de Tierras de contribuir a la reconstitución, en términos económicos, de los antiguos patrimonios comunales expropiados en la Zona; aspecto que constituyó un importante elemento en la negociación política - previa a la elaboración de la norma-con los Ayuntamientos implicados en la zona de Bárdenas, según expondré más adelante. Pues bien, a los Ayuntamientos que vean reconstituidos sus patrimonios comunales se les impone una gestión de los mismos conforme al régimen del Banco de Tierras; imposición que viene facilitada mediante la integración temporal voluntaria y, en su caso, onerosa, en el propio Banco de Tierras.

d) Por último, pueden integrarse en el Banco de Tierras otros inmuebles de destino agrario pertenecientes a la Comunidad Autónoma o adquiridos por el Ente Gestor del Banco de Tierras (arts. 12 y 13).

En la somera descripción realizada de los bienes que pueden integrar el Banco de Tierras se observará que no hay supuestos de inclusión obligatoria por la Administración de ciertas categorías de inmuebles. En todo caso corresponde adoptar una decisión discrecional sobre tal extremo a la Diputación General de Aragón o a otro Ente público: decisión de afectar tierras adquiridas en procedimientos de transformación de Grandes Zonas; decisión de ejercer los derechos preferentes de adquisición; decisión de ceder el uso de comunales; decisión de afectar otros bienes.

Importa destacar este aspecto, con frecuencia olvidado, porque pone de relieve la adaptabilidad del sistema de la Ley del Banco de Tierras a las diversas opciones políticas que puedan sucederse en el Gobierno de la Comunidad Autónoma. No es una Ley excluyente. A un Ejecutivo contrario a la filosofía de la norma le basta con no incluir bienes en el Banco de Tierras para evitar la aplicación de la Ley

Incluso, en este sentido, la propia Ley prevé la desafectación de bienes del Banco de Tierras mediante Decreto adoptado por la Diputación General de Aragón (art. 14.2). Sólo en el caso de los bienes adquiridos en procedimiento de transformación de Grandes Zonas se impone una reserva de Ley para la desafectación, de cara a 
obtener una mínima estabilidad en la gestión del Banco de Tierras (art. 14.1).

Para terminar ya con este punto, señalaré que la Ley del Banco de Tierras no se pronunció sobre la naturaleza jurídica de estos bienes, entendiendo que el problema debía ser resuelto conforme a los criterios generales aplicables a todos los bienes de la Comunidad Autónoma.

La Ley Aragonesa del Patrimonio (Ley 5/1987, de 2 de abril) fuerza a concluir la consideración de los bienes del Banco de Tierras como bienes demaniales, según ha demostrado Tudela en el estudio antes citado. En efecto, la Ley del Patrimonio regula en su artículo 30 la valoración de mejoras a la extinción de las concesiones del Banco de Tierras, dentro del título referido a los bienes demaniales de la Comunidad Autónoma.

\section{D) Explotación del Banco de Tierras}

El destino de los bienes del Banco de Tierras se decide por el Ente Gestor del mismo, conforme a unos criterios especificados en la Ley (art. 16). Prioritariamente, las tierras deben destinarse a complementar explotaciones familiares agrarias, a fin de que sean viables social y económicamente; destino preferente que muestra la adherencia de la Ley a las necesidades de los ámbitos municipales en que se aplique.

Otros destinos posibles de los bienes del Banco de Tierras consisten en la constitución de explotaciones agrarias familiares o comunitarias y, excepcionalmente, el establecimiento de campos de experimentación.

En todo caso, para cada explotación se exige una concesión administrativa otorgada por el Ente Gestor, previo concurso público; concesión que es intransmisible e inembargable (arts. 19 y 20). El concesionario asume, so pena de declaración de caducidad, las obligaciones de cultivar directa y personalmente la explotación (obligación que en las explotaciones comunitarias recae sobre los socios), alcanzar las cuatro quintas partes de los mínimos de producción que fije el Ente Gestor del Banco de Tierras, permitir la ejecución de obras, ejecutar las mejoras previstas y pagar el canon concesional que establece también el Ente Gestor (art. 22).

Para la adjudicación de las concesiones de explotación familiar y complementaria, el Ente Gestor aprueba unas bases en las que se valoran la vecindad en los Municipios afectados, la condición de cultivador directo y personal o colaborador en el cultivo de tierras expropiadas en la zona, la dedicación profesional a la agricultura, la carencia o escasez de propiedades, la cualidad de agricultor joven, el 
nivel de ingresos, las cargas familiares y la posesión del título de capacitación agraria (art. 25). Estas concesiones son vitalicias, salvo el supuesto de jubilación o cuando inciden sobre bienes cedidos por plazo determinado al Banco de Tierras (art. 26).

Preocupación de la Ley del Banco de Tierras ha sido el conferir un sentido económico efectivo a la relación del concesionario con la explotación, lo que se consigue con el indicado carácter vitalicio de estas concesiones y, también, a través de dos instrumentos. Uno es el derecho a obtener nueva concesión sobre la misma explotación, extinguida la anterior relación concesional; derecho que se reconoce, conforme a determinados criterios de prioridad, en favor del cónyuge, de los hijos y de los colaboradores en la explotación del primitivo consesionario (art. 27). Otro instrumento que proporciona contenido económico efectivo a la concesión es el derecho a la valoración y pago de las mejoras introducidas, derecho ejercitable cuando se extinga la relación concesional (art. 28). De esta manera, se permite una suerte de «sucesión» en la explotación, no gravada por el pago de legítimas hereditarias, salvo en lo referido al valor de las mejoras.

En cuanto a las concesiones de explotación comunitaria, debe resaltarse que se otorgan en favor de Sociedades Agrarias de Transformación o entidades de base cooperativa, cuyos socios asumen la obligación del cultivo personal (art. 29). Estas concesiones se otorgan por plazo de treinta años, renovables mientras se mantenga el carácter de la explotación (arts. 31 y 32). Siempre, en caso de no renovación, hay derecho al pago de las mejoras útiles y subsistentes (art. 33).

\section{E) Gestión del Banco de Tierras}

Para la gestión de los bienes del Banco de Tierras, la Ley constituye un organismo autónomo representativo, con la denominación de Ente Gestor del Banco de Tierras (art. 35 y ss.).

Importa destacar que el máximo órgano de gobierno del Ente es un Consejo de 21 miembros, 11 de los cuales se vinculan a la Diputación General de Aragón y los 10 restantes a Ayuntamientos, otros Entes públicos, asociaciones y sindicatos agrarios (arts. 41 y 42). Se observará que, aun correspondiendo la mayoría en el Consejo a la Diputación General de Aragón -extremo que parece muy lógico, pues se trata de gestionar un patrimonio de la Comunidad Autónoma-, hay una fuerte representación de los interesados.

En cualquier caso, la ordinaria marcha del Ente Gestor es asegurada por el Gerente, nombrado y cesado libremente por la Diputación General de Aragón, previo informe preceptivo del Consejo del Ente Gestor (art. 44). El Gerente es órgano clave en el diseño del 
organismo autónomo puesto que se beneficia de la competencia residual (art. 48). De haberse puesto en marcha los mecanismos del Banco de Tierras, no cabe duda que una buena parte del éxito o del fracaso de la institución hubiera dependido precisamente del acierto político y técnico en la elección del Gerente. Una persona con amplios conocimientos técnicos en agricultura, bien considerada en los ambientes rurales, con capacidad negociadora...

Otros órganos previstos eran la Comisión Permanente y el Secretario del Ente Gestor (arts. 43, 45, 47 y 49).

\section{UNA LEY DE ORIGEN MUNICIPAL Y DE FINALIDAD ANTIDESAMORTIZADORA}

\section{A) Los acuerdos sobre comunales de 1984}

La idea política que dio origen a la Ley del Banco de Tierras se fraguó en torno a las dificultades de la transformación en regadío de la zona regable por la segunda parte del canal de Bárdenas. La transformación de Bárdenas II se inició con un Decreto de 1 de julio de 1971, que declaraba el interés nacional de la operación, cumpliéndose después los sucesivos pasos, hasta llegar a la expropiación de las tierras en exceso, conforme a la legislación colonizadora, refundida en 1973 en la Ley de Reforma y Desarrollo Agrario.

La problemática específica de la zona venía determinada por la existencia de grandes masas de bienes comunales, fuente de numerosos conflictos entre los Ayuntamientos y los vecinos. Ante la amenaza de la desaparición de los patrimonios municipales, caso de aplicación estricta de la Ley de Reforma y Desarrollo Agrario, surgió la idea de formar el Banco de Tierras.

Esta idea se reflejó en unos Acuerdos sobre expropiación de comunales suscritos en 1984 por el IRYDA, la Diputación General de Aragón y los Ayuntamientos de Pradilla de Ebro, Tauste y Ejea de los Caballeros. En dichos Acuerdos, los Ayuntamientos se comprometieron a no cuestionar políticamente la expropiación de los comunales, siempre y cuando se modificaran las normas sobre uso y adjudicación de los lotes formados con los bienes expropiados. Básicamente, el germen que condujo al Banco de Tierras consistía en la idea de asegurar la propiedad pública de los lotes, que debían ser objeto de explotación mediante concesiones administrativas, bajo un control 
público ejercido por un Ente de carácter representativo de los intereses afectados.

En contrapartida al compromiso municipal, el IRYDA y la Diputación General de Aragón aseguraban la reconstitución de los patrimonios comunales; concretamente, la cuarta parte de la superficie comunal expropiada, una vez transformada en regadío, debía volver a los Ayuntamientos, quienes integrarían voluntariamente los bienes en el Banco de Tierras o, en todo caso, los explotarían conforme el régimen jurídico establecido para el mismo Banco de Tierras.

\section{B) El fundamento antidesamortizador}

El objetivo último de los Acuerdos de 1984 consistía en evitar la desamortización de unos bienes públicos. Sabido es que la desamortización civil constituyó, junto con la eclesiástica, un elemento fundamental en la política liberal decimonónica, alcanzando su punto álgido con la Ley Madoz de 1855. La filosofía que apoyaba la operación desamortizadora podría resumirse en la idea de que los Entes públicos no debían ser ni propietarios ni empresarios, correspondiendo, en consecuencia, al poder político la misión de enajenar todas las propiedades públicas que no fueran estrictamente necesarias para el cumplimiento de funciones públicas. Filosofía de amplio desarrollo temporal, pues no cabe olvidar que la Legislación desamortizadora general se mantuvo formalmente en vigor hasta el siglo $x x$, en que se produjo su derogación con el Estatuto Municipal de 1924 para las Administraciones locales y con la Ley del Patrimonio del Estado de 1964 para la Administración del Estado.

Sin embargo, la derogación expresa de la legislación desamortizadora general no ha impedido la vigencia de planteamientos acordes con su filosofía de base en diversos sectores de actuación pública. Uno de ellos, precisamente, es el contemplado por la legislación colonizadora: grandes patrimonios adquiridos por el Estado en zonas con abundantes comunales se transformaban en regadío con enormes inversiones públicas, para luego adjudicar en propiedad los lotes resultantes. Sin que, por añadidura, esa legislación asegurara el mantenimiento de la reforma agraria (esto es, de las explotaciones de tipo medio constituidas), frente a la natural tendencia a la concentración de la propiedad.

Con el Banco de Tierras se pretendía formar un patrimonio agrícola en mano pública que fuera el hilo conductor de una reforma agraria permanente. Una reforma basada en el cultivo personal y directo de las explotaciones; que ofreciera una estabilidad al agricultor, permitiéndole seguir al frente de la explotación de por vida 
e, incluso, asegurando derechos a la continuidad en dicha explotación por parte de sus descendientes; una reforma que, no obstante, permitiera mantener la titularidad pública de los bienes afectados.

Antecedente parcial de la idea del Banco de Tierras puede encontrarse en el diseño inicial de la Ley de Reforma Agraria de 1932, bajo la Segunda República. También aquí el Estado conservaba la propiedad de las tierras objeto de asentamientos. Aunque las diferencias entre uno $y$ otro supuesto resultan asimismo claras: el origen de las tierras sobre las que operaba la Ley de 1932 estaba relacionado con supuetos incumplimientos de la función social de la propiedad -incumplimientos que se identificaban, muy característicamente, en los latifundios-, mientras que los bienes del Banco de Tierras proceden, como consecuencia ineludible, en el caso más destacado, de una operación pública de transformación de una Zona en regadío.

En definitiva, dentro de un contexto antidesamortizador hay que entender las previsiones de la Ley del Banco de Tierras sobre los comunales; previsiones a las que ya he hecho alguna referencia. EI artículo 5 de la Ley permite a la Diputación General de Aragón convenir con los Ayuntamientos el pago del justiprecio de los comunales expropiados con la transmisión de tierras transformadas en regadío, asumiendo los Ayuntamientos el compromiso de explotar el patrimonio comunal reconstituido conforme a las pautas del régimen jurídico del Banco de Tierras. Se supera, así, la limitación que, en otro caso, determinaba el artículo 92 de la Ley de Reforma y Desarrollo Agrario, al exigir, en la expropiación de tierras en exceso, el pago del justiprecio precisamente en dinero. Regla ésta de la Ley de Reforma y Desarrollo Agrario que se justifica en la razón de evitar que la aplicación de la norma más flexible contenida en la legislación general expropiatoria (art. 48 de la Ley de Expropiación Forzosa) imposibilitara la misma reforma agraria; en efecto, si se permitiera el pago de las tierras expropiadas con tierras transformadas no habría posibilidad práctica de constituir lotes para nuevas explotaciones. Dentro de la filosofía de la Ley del Banco de Tierras, la regla del pago fozoso del justiprecio en dinero para los comunales expropiados ya carece de sentido, puesto que el mantenimiento de la reforma agraria se logra con el patrimonio comunal explotado conforme al régimen jurídico del propio Banco de Tierras.

Para facilitar a los Ayuntamientos esa aplicación del régimen jurídico del Banco de Tierras, el artículo 9 de la Ley, antes examinado, permite a los Ayuntamientos integrar con carácter temporal en el Banco de Tierras los mismos patrimonios comunales reconstituidos; cesión que, incluso, puede ser a título oneroso. 


\section{UNA LEY PARA LA REFORMA AGRARIA PERMANENTE}

La Ley del Banco de Tierras, con todos sus posibles defectos, es una Ley que ha posibilitado la práctica de una reforma agraria permanente. Afirmación ésta que hago muy conscientemente, a la vista de una serie de contenidos de la Ley que me gustaría resaltar.

La Ley permite el acceso a la titularidad de la empresa agraria del agricultor modesto. Titularidad empresarial que no está basada en la propiedad de la tierra, ciertamente, al contrario de lo que sucede en el sistema de la Ley de Reforma y Desarrollo Agrario. Sin embargo, para calibrar el alcance en este punto de la Ley del Banco de Tierras, es preciso tener en cuenta el alto precio que debería pagarse por los lotes, caso de entrega en propiedad. Por eso digo que el Banco de Tierras está decididamente inclinado en favor de un tipo concreto de agricultor, el agricultor modesto.

La Ley garantiza la permanencia del cultivo personal y directo de las explotaciones, al exigirlo en todo caso para el mantenimiento de la correspondiente concesión. Se trata, así, de contribuir a la formación de esa clase media en los ámbitos rurales, que ha sido el constante objetivo de la Legislación agraria española.

La Ley evita, sin duda, la tendencia a la concentración de la propiedad, pasada la primera generación de colonos, en las Zonas transformadas en regadío.

La Ley elimina el conocido problema derivado de la sucesión del hijo colaborador en la explotación. Dentro del sistema de la Ley de Reforma y Desarrollo Agrario, con frecuencia, ese hijo (estamos ante un supuesto prototípico) debía endeudarse con frecuencia de por vida, para pagar a sus hermanos la parte de legítima que les correspondiera en la herencia. Tales problemas desaparecen en la concesión del Banco de Tierras, puesto que el hijo colaborador no hereda la explotación, sino que tiene derecho a obtener una nueva concesión.

La Ley mantiene, sin embargo, el interés económico del cultivador, pues establece el derecho al pago de las mejoras introducidas en la explotación, al extinguirse la relación concesional.

La Ley introduce nuevas fórmulas para lograr la modernización de las explotaciones agrarias, mediante la fijación de unos índices de producción y la imposición de unas mejoras obligatorias por el Ente Gestor del Banco de Tierras.

Por último, resaltaré que todos esos contenidos de la Ley son llevados a la práctica por un organismo - el Ente Gestor- en cuya 
estructura los diversos sectores interesados cuentan con amplia participación.

¿Defectos? Claro que los habrá. Pero posibilidades, elementos positivos y factores de ilusión, también existen en la Ley Aragonesa del Banco de Tierras.

\section{UNA LEY INAPLICADA Y PENDIENTE DE DEROGACION}

\section{A) La inaplicación}

Las Leyes, por sí solas, no modifican la realidad social. Hoy estamos lejos de aquella «mística de la Ley», generada en los inicios de las revoluciones burguesas, conforme a la cual bastaba con la aprobación parlamentaria de una regulación para que, inmediatamente, se produjeran las transformaciones sociales propugnadas en su texto. Probablemente, en la evolución operada ha incidido la complicación normativa inherente a las sociedades avanzadas; pero, en todo caso, hoy nos consta que una Ley se queda en meras palabras si no es efectivamente llevada a la práctica.

La aplicación de la Ley del Banco de Tierras dependía enteramente del Ejecutivo aragonés. En un primer momento, el Ejecutivo socialista - promotor de la Ley- acordó la integración en el Banco de Tierras de unas 4.500 hectáreas, por Decreto 47/1987, de 8 de mayo. Pero, poco después, tras las elecciones de junio de 1987, el Gobierno del Partido Aragonés Regionalista paralizó la aplicación de la norma. Legítimamente, tal como antes expuse, la Diputación General de Aragón ha podido tomar la decisión de no efectuar nuevas adscripciones de tierras; tal posibilidad la permite la propia Ley aprobada por las Cortes aragonesas. Mayores dudas de legitimidad provoca, en cambio, la no constitución del Ente Gestor del Banco de Tierras dentro del plazo de seis meses que fijaba la Disposición final primera de la Ley.

\section{B) La proposición de Ley sobre el Patrimonio Agrario}

La Ley del Banco de Tierras no se ha. aplicado y, además, está pendiente de derogación. El Boletín de las Cortes de Aragón de 5 de octubre de 1988 publicaba, en efecto, la Proposición de Ley sobre Patrimonio Agrario, suscrita por el Centro Democrático y Social; partido político que cambia, así, su inicial postura de apoyo a la Ley. del Banco de Tierras - postura conseguida, por cierto, no sin amplias concesiones, que accedieron, en forma de enmiendas aceptadas, al texto de la Ley. 
La proposición centrista incorpora novedades, con respecto a la Ley del Banco de Tierras, pero también presenta criterios de continuidad y genera problemas importantes.

Hay novedades. La primera es que la proposición afecta a todos los inmuebles susceptibles de explotación agraria sobre los que la Comunidad Autónoma de Aragón ostente algún derecho real. Dado que la opción, en lo relativo al sistema de explotación, está claramente decantada por la adjudicación en propiedad, cabe concluir que se trata de una propuesta de signo desamortizador. Así se deduce, en todo caso, del artículo 3.1.d) de la proposición, que considera principio básico «evitar la acumulación abusiva de la propiedad agraria de origen público»; aunque se hable evitar la acumulación abusiva, lo que se persigue, como veremos, es evitar la propiedad agraria pública.

Otra novedad relevante es el principio de libre elección del adjudicatario de una explotación entre la adquisición en propiedad o la vía concesional; principio que opera teóricamente en todos los supuestos, salvo cuando se trata de bienes objeto de derechos reales limitados por parte de la Comunidad Autónoma, caso en el que sólo es admisible la concesión. Sucede, sin embargo, que el régimen se decanta claramente en favor de la fórmula propietaria: a) Los precios de las explotaciones se fijan por el Instituto Aragonés del Patrimonio Agrario, sin ningún condicionante derivado de los costes, en su caso, de la transformación en regadío; bastará, pues, con que el Instituto sea algo generoso en la fijación de esos precios. b) La adquisición del dominio pasa por un período de acceso diferido a la propiedad, durante el que van pagándose los plazos del precio establecido; pues bien, para el caso de que no llegue a completarse el pago del precio, se establece un derecho de reintegro de los anticipos; en consecuencia, en tal supuesto, el uso de la tierra durante un cierto período de tiempo habrá sido gratuito. c) La adquisición del dominio se produce, además, con independencia del pago del precio.

Novedades a valorar. También, elementos de continuidad. Como sucede con los criterios de fondo para las adjudicaciones de tierras, que siguen las pautas promotoras del cultivo directo y personal identificables en la Ley del Banco de Tierras. Como ocurre en los aspectos organizativos, con la figura de lo que ahora se denomina Instituto Aragonés del Patrimonio Agrario, cuya regulación sigue de cerca la relativa al Ente Gestor del Banco de Tierras.

Novedades. Continuidad. Problemas, por último. La proposición centrista olvida por completo la problemática de los bienes comunales afectados, aspecto que acentúa el carácter desamortizador de la propuesta. La toma de decisiones a propósito del destino de bienes 
públicos se traslada de los órganos políticos y administrativos a los particulares. No hay garantía de permanencia de la reforma agraria, esto es, del mantenimiento de las explotaciones de tipo medio que persigue la transformación de Grandes Zonas; todo se fía, en tal sentido, al juego de unos derechos de adquisición preferente en favor de la Comunidad Autónoma - mecanismo que es secundario en la Ley del Banco de Tierras-, olvidando que para el ejercicio de los tanteos y retractos hace falta mucho dinero o, en caso contrario, el arbitrio de mecanismos para contrarrestar la especulación. No se vislumbra en la proposición de Ley un intento modernizador efectivo de la agricultura, habiendo desaparecido la figura de los índices de producción. Desde la óptica organizativa, a la vista de la opción propietaria que se mantiene, cabe preguntarse si tiene sentido mantener la fórmula del organismo autónomo, de la personalidad jurídica propia del llamado Instituto Aragonés del Patrimonio Agrario; ¿no sería suficiente constituir alguna Comisión representativa en el seno del Departamento de Agricultura?

En último extremo, la proposición de Ley se traduciría en un sistema de resultados tan similares al regulado en la Ley de Reforma y Desarrollo Agrario, que no acaba de comprenderse la necesidad de una específica Ley Aragonesa. 